\title{
Survey on early career travel support shows geographic, career stage, and indigenous status inequality in access to polar science events
}

\author{
Alice Bradley ${ }^{1}$, Juan Höfer ${ }^{2}$, Valentina Savagliaa ${ }^{3,4}$, and Clare Eayrs ${ }^{5}$ \\ ${ }^{1}$ Williams College, Williamstown, USA \\ ${ }^{2}$ Escuela de Ciencias del Mar, Pontificia Universidad Católica de Valparaíso, Valparaíso, Chile \\ ${ }^{3}$ University of Liège, Liège, Belgium \\ ${ }^{4}$ Ghent University, Ghent, Belgium \\ ${ }^{5}$ Center for Global Sea Level Change, New York University Abu Dhabi, Abu Dhabi, United Arab Emirates
}

Correspondence: Alice Bradley (alice.c.bradley@williams.edu)

Received: 1 December 2019 - Revised: 6 May 2020 - Accepted: 17 May 2020 - Published: 25 June 2020

\begin{abstract}
Scientific meetings, conferences, field schools and workshops provide essential networking and training opportunities for early career researchers, but in highly international fields like polar sciences, attending these events can involve extensive travel. We surveyed Association of Polar Early Career Scientists members and other early career members of the polar science community to investigate the geographic and international variability in travel support relative to costs across the early stages of a researcher's career (Masters students, PhD students, post-docs and those in faculty or permanent research positions). 190 respondents from 38 countries answered questions on the perceived availability of different types and sources of travel funding and described up to three events they attended over the last two years. We found that the cost of attendance prevented nearly three-quarters of respondents from participating in at least one career-relevant events in the preceding two years. Due to insufficient research funding, early career researchers frequently have to top up partial support with personal funds. Increased event-based travel support would help to reduce out of pocket expenses, as would the timely notification of a travel award to benefit from early bird registration and cheaper travel and accommodation. Replacing the more common practice of travel reimbursement with a travel advance would remove another barrier to attendance. Large disparities in what kinds of expenses are covered exist between geographic regions and funding mechanisms. Addressing the disparities in travel support for career-relevant events will
\end{abstract}

promote diversity and foster inclusion in the next generation of polar scientists.

\section{Introduction}

In order to make progress in their fields, early career researchers (ECRs) must attend scientific meetings. Conferences provide the opportunity to present their work and meet future colleagues. Smaller workshops are a setting for closer collaboration and knowledge exchange within an area of specialization. Field schools and workshops can be the only available opportunity for advanced education in a particular sub-discipline.

In highly international fields like polar sciences, attending these meetings and workshops can require extensive travel: for example, in November 2019, 11 meetings or conferences took place in eight countries for Arctic work alone (ARCUS, 2019). This costs money: travel funding support is therefore required for early career researchers to make progress in their respective careers. Funding for early career travel can come from a number of sources, including institutional grants or travel allowances, research grant budgets, provided by the event organizers, or as a small travel grant from organizations, national funding bodies, or private foundations. For some early career researchers though, these sources are not adequate for their career needs and their professional travel must be paid out of pocket. 
Diversity in polar science has been an ongoing concern since at least before the 2007-2008 International Polar Year. A major theme of the "Bridging the Poles: Education Linked with Research" workshop (Pfirman, 2004) was engaging diverse communities in polar science, and workshop reports emphasized the need for increased efforts to include Arctic Natives and residents, minorities, gender diversity, along with geographic, socioeconomic, and international diversity. These concerns have not changed in the intervening fifteen years: diversity in polar science remains an issue to this day (Gewin, 2019).

There is a concerted effort in the broader Arctic community to better integrate indigenous perspectives into the Arctic scientific research process. The Arctic Council Agreement on Enhancing International Arctic Scientific Cooperation specifically calls on nations to "encourage holders of traditional and local knowledge, as appropriate, to participate in Scientific Activities" (Article 9.3, Arctic Council, 2017). The International Arctic Science Committee's strategic plan lists "Supporting participation by Indigenous and local residents in science activities" as one of the key components of their Promoting Engagement activities (IASC, 2018). Some national funding agencies have issued guidance on incorporating community knowledge and participants into the research process (i.e., IARPC, 2018). Attending meetings and workshops is an important scientific activity for disseminating information, building networks, and for getting credit for contributions to scientific understanding.

\subsection{Travel in a scientific career}

Engaging in scientific meetings and with the scientific community in a field has long been considered critical to the success of an early career researcher (Urban, 2013). Support and mentoring for meeting attendance was the cornerstone of the Association for the Sciences of Limnology and Oceanography Multicultural Program efforts to increase diversity in the field (Cuker, 2016). Networking at meetings is so important that workshops exist to help groups underrepresented in the field improve their networking skills (Gleßmer, 2012).

This has been shown in the polar sciences as well. A 2016 article evaluated surveys on career outcomes for ECRs who did and did not receive travel funding through an International Arctic Science Committee (IASC) funding call in 2009-2013. Those who received funding reported that it helped with their research, career, and engagement with the organization (Majaneva, 2016). While this study lacked a strict control group (those selected for funding were deemed most qualified at the time), it did highlight that events that had the most significant impacts for career outcomes were those where an ECR played a more active role. This would suggest that small workshops and research community meetings might prove to be a more useful investment of money for travel support than a larger scientific conference when it comes to this stage of career development.

\subsection{Paying for travel}

Anecdotally, it has long been clear that many early career researchers are using personal funds to attend meetings. It is common to find many graduate students sharing a hotel room or rented apartment, trying to stretch limited travel funding to cover something closer to the full cost of a trip to a conference. While many scientists attempt to cut costs to stretch limited travel funds, younger researchers are known to tolerate conditions (i.e., sharing beds or sleeping on the floor) that would be unacceptable to most senior scientists.

While the use of some personal funds to fund travel may be common practice, it is important to consider that graduate student and postdoctoral researcher salaries are often quite low. A 2017 study found the average post-doc salary in the US to be USD 47000 (EUR 43 000) (Bankston, 2017), and globally this number is most likely somewhat lower. In many cases then, spending even EUR 500 (USD 550) amounts to slightly more than $1 \%$ of pre-tax annual pay and can present a financial hardship to researchers who may also be dealing with student debt, starting a family, or the cost of living in an expensive university community. PhD students typically receive lower pay, often in the range of USD 20-30000 in the US (EUR 18-27k, Green, 2017).

In polar sciences, meetings and workshops typically have some budget available to support early career participation (a practice we recommend across the geosciences). The typical approach is to invite early career researchers (the definition varies, but it is often up to 5 years following completion of a PhD) to submit an application for travel support. This is primarily intended to include graduate students (including Masters students), postdoctoral researchers (herein postdocs), and people starting in non-academic research positions. Applications may require a submitted abstract, a statement regarding why they would like to attend the conference, what they hope to get out of it, and an estimated travel budget. Meeting organizers, or an external group (often organized through the Association of Polar Early Career Scientists, APECS), will then evaluate applications on a number of criteria including relevance to the meeting, the quality of the submitted abstract, and career stage. There may be additional selection criteria added at this point in order to promote diversity in the attendees (e.g., SEARCH, 2019), though the funding source may limit the countries that are considered (e.g., SCAR, 2019a; IASC, 2019a). Accepted applications may be awarded full or partial travel support, based on the total available budget and the beliefs of those making the awards about the cost of travel and potential other sources of funding. These calls for travel support are often very competitive (e.g., Provencher, 2012).

Organizations in polar sciences also use travel funding as a mechanism for involving early career researchers in their working groups and committees. The IASC Fellows program takes one new early career fellow per year for each of their five working groups, funding travel to the two annual Arc- 
tic System Science Week meetings for that bookend the one year of active fellowship period. The fellowship application is highly competitive, with roughly a $5 \%$ acceptance rate over the last few years (IASC, 2019b). APECS annual reports documented a total of 38 organizational roles for early career researchers through IASC, the Scientific Committee for Antarctic Research (SCAR) and other organizations, many of which involved funded travel (APECS, 2018).

This study investigates the funding-related factors that could make professional travel more difficult for early career researchers in some demographic areas: the differing funding landscape for Arctic Indigenous peoples (those whose traditional homelands are in the Arctic) and residents, and geographic and international variability in travel support relative to costs. In order to improve diversity in polar sciences, there must be opportunities for underrepresented groups to succeed. While traveling to meetings and workshops is required for networking and building up a research community, inequalities in travel support can only exacerbate the homogeneity of the polar research community.

Disproportionate financial burdens of attending the meetings and workshops that are critical to career development can therefore have a negative impact on both the individual early career researchers and on the diversity of the polar science field as a whole (MoChridhe, 2019). This study used a survey of APECS (Association of Polar Early Career Scientists) members and other early career members of the polar science community to gather data on the landscape of travel support availability around the world and across stages of a researcher's early career.

\section{Survey}

A survey was sent twice to APECS members, once in June of 2019 and again in late August. This was emailed out to slightly over 3000 people. It was also sent to the Cryolist email list, shared with participants at three workshops/conferences, and distributed among the APECS leadership. The email and survey header described the project, that this information was meant to better inform organizations that fund travel support for early career researchers, and made it clear that no identifying information would be shared or published. The survey took about $15 \mathrm{~min}$ to complete.

\subsection{Survey questions}

The survey included five sections: basic information, general questions about their available travel support, questions about their ability to fund travel to a hypothetical meeting in their field of research, a section to describe how their last three research-related event travel experiences were funded, and an opportunity to provide additional comments. The survey questions are included in full as a Supplement.
Basic information included: country where they work/study, current position/career stage, how their position is funded, how many of several types of events (e.g., scientific conferences versus field schools) they have been to in the last three years. Respondents were asked if they are indigenous or a resident of a northern community: in accordance with IASC AGII (2020), self-identification is only necessary standard. The two groups (Indigeneous peoples and northern community memebers) are grouped together to reflect similar structural challenges to participation.

Available travel support questions included: eventprovided travel source, research grant that funds their project, organization support for ECR representative travel, Institutional travel grant, national funding body travel grant, private foundation travel grant.

Meetings attended during the past two years questions included: the kind and the number of meetings they could attend, the type of expenses covered, the amount of money spent during three hypothetical meetings in Europe or the United States, the number of work-related events covered per year, the need for a travel advance to participate and how to seek for a travel funding to attend these kind of events.

Last event/activity/meeting/conference questions included: what kind, whether or not the travel was international, the amount of money that was spent, the distance traveled, the need to present a poster or an oral communication, to have a formal organizational role or need to volunteer to participate in this event, where the funding was coming from and the perceived availability of alternate travel funding sources, the nature of the choice to participate in this event.

A few additional questions addressed whether they had been unable to attend an important meeting during the past two years because of attendance costs, and left a space for any additional comments on the availability of travel support.

\subsection{Survey responses}

190 individuals went on to fill out the survey, mostly within a few days of these emails. For comparison, on the first of October 2019 there were 3154 APECS members (defined as those who joined or actively opted to stay on the email list over the last three years), spread over 73 countries. The responses analyzed below may disproportionately represent individuals who have traveled significantly over the last three years and/or those who are unhappy about the amount of travel support they receive.

These responses came from a range of career stages and countries, as shown in Table 1 . PhD students and postdocs together comprised $70 \%$ of the responses, with faculty or other permanent research positions and then masters students as the two next largest categories. All other career stages (undergraduates, educators, and others) made up $7.4 \%$ of the responses.

Responses came from 38 countries, the most popular of which were the US (36), Canada (17), Germany (13), UK 
Table 1. Number of responses by demographic group considered in this study. The number in parenthesis indicates the number of respondents from each continent who identified as Indigenous or a northern community resident.

\begin{tabular}{lrrrrrrrr}
\hline & Masters & PhD & Postdoc & Faculty & Other & $\begin{array}{r}\text { Total by } \\
\text { continent }\end{array}$ & $\begin{array}{r}\text { Fraction } \\
\text { responses }\end{array}$ & $\begin{array}{r}\text { APECS } \\
\text { membership }\end{array}$ \\
\hline North America & 5 & 26 & 9 & 10 & 1 & $51(4)$ & $27 \%$ & $28 \%$ \\
South America & 3 & 2 & 6 & 7 & 2 & 20 & $11 \%$ & $7 \%$ \\
Europe & 5 & 39 & 27 & 5 & 4 & $80(2)$ & $42 \%$ & $38 \%$ \\
Asia (incl. Russia) & 1 & 6 & 4 & 3 & 5 & $19(4)$ & $11 \%$ & $10 \%$ \\
Oceania & 2 & 6 & 4 & 1 & 0 & 13 & $7 \%$ & $5 \%$ \\
Africa & 0 & 2 & 2 & 1 & 1 & 6 & $3 \%$ & $2 \%$ \\
\hline Total by career stage & 16 & 81 & 52 & 27 & 13 & & & \\
\hline
\end{tabular}

(11), and Australia (9). $43 \%$ of responses came from Europe, $27 \%$ from North America, $11 \%$ South America, $10 \%$ Asia, $7 \%$ Oceania, and $3 \%$ Africa. The geographic distribution tracks with the APECS membership numbers (listed in Table 1), suggesting that this survey did not suffer from large biases in geographic representation. 10 survey participants reported belonging to an indigenous or northern community. These groups, while distinct, both face challenges related to funding resources and travel to/from remote locations and are grouped together in this analysis.

Respondents reported on their funding for travel to 320 non-fieldwork events, with up to three events per survey, all occurring over the last two years. As is described in more detail in Sect. 3.1., some early career researchers do not travel often enough to have made three trips in the last two years. Others may have chosen not to describe all their travel for privacy or other reasons, or may have mostly traveled for reasons like field work that were not addressed in this survey.

\subsection{Survey Analysis}

In order to protect the anonymity of the survey respondents, only aggregate data is presented herein. A country and the last few meetings someone attended would, in many cases, be adequate to identify them, so individual meetings and workshops are not listed here.

Survey responses were grouped according to four primary factors: career stage, continent where they work, how their positions are funded, and Indigenous status. All survey respondents provided their country, career stage, and funding status. Seven of the 190 responses did not answer "Are you an Indigenous/northern community member?" and were grouped with the "no"s for analysis. Career stages considered herein are Masters students, PhD students, post-docs, and those in faculty or permanent research positions. Other career stages were too few in number of reports to generate statistics. We are not considering undergraduate and the "other" career stages because of limited numbers or ambiguous answers.
Countries were grouped into six regions: Europe, North America, South America, Oceania, Asia, and Africa. Russia and Turkey, despite spanning multiple continents, were grouped in with Asia rather than Europe. This was done partly because we have no additional data regarding where in the countries the responses were coming from, but primarily because Russia and Turkey lack access to funding programs available through the EU that most other European nations can participate in.

When asking ECRs about the number of different types of trips they have taken over the last two years, the survey gave them options for $0,1,2,3$, or more than three trips of a given category. For the purposes of analysis, we assumed that "more than three" meant on average five trips. This was a limitation of the survey setup on Google Forms.

\section{Results}

Key results from the survey data fell under a few categories: the frequency with which different groups of ECRs traveled for various research-related events, the cost per trip and the associated factors, how those trips were funded, features of travel funding including partial support and travel advances, and what expenses are covered for different groups.

\subsection{Number of trips}

ECRs that responded to this survey traveled for reasons related to their research an average of 8 times over the previous two years (including field research). This number ranged from 7.8 events over two years for $\mathrm{PhD}$ students to 8.5 events over that period for faculty. Despite the fact that polar organizations tend to prioritize indigenous candidates in their distribution of travel funding (e.g. Arctic Council (2017) Article 9.3), indigenous respondents only averaged 5.3 events over the two years, which suggests that the current funding opportunities are insufficient, or insufficiently advertised, to enable equality of access to Indigenous ECRs. Those from Oceania and Africa traveled the most, with 11.2 and 10.6 


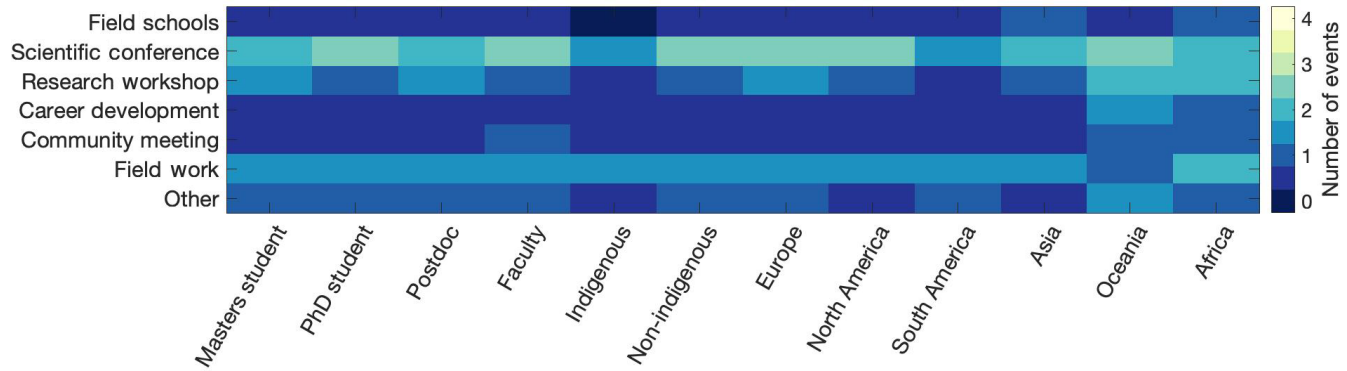

Figure 1. Mean number of events attended over two years by event type and demographic group.

trips reported. ECRs from South America traveled the least, with only 6 trips over that two year period.

A small number of ECRs traveled a lot: 23 individuals made at least 15 trips in the preceding two years. These were often graduate students or post-docs that were working with two different research groups and required frequent travel between two institutions or making many trips per year for field work. This was most likely in Europe, with 11 individuals as compared to 5 from North America, 4 from Oceania, and 1 each from the other regions.

\subsubsection{Scientific conferences}

Scientific conferences were the most popular type of event to which respondents traveled, with an average of 2.5 meetings over that two year period. $92 \%$ of respondents attended at least one conference during this time. Faculty attended the most conferences, averaging 3 meetings, but all career stages including Masters students attended more than 1 per year on average. All faculty who responded to this survey attended at least one conference during this time. Indigenous respondents and ECRs from South America attended the fewest, with only 1.5 and 1.7 over the reporting period, respectively and those from South America were the most likely to have not attended a conference at $20 \%$. The low attendance of Indigenous ECRs at scientific conferences reflects the overall finding that this is a group that has less access to careerenhancing activities despite the fact that the Arctic community aims to better integrate indigenous perspectives in the Arctic scientific research process.

\subsubsection{Field work}

The second most common reason for travel was field work, averaging 1.5 trips over two years. The groups that had more fieldwork trips than average were the opposite than for other types of travel: indigenous people and those from South America and Africa traveled 1.8, 2.0 and 2.0 times respectively, though for both indigenous ECRs and those from South America this meant a lot of field work travel was concentrated in a subset $(50 \%$ and $35 \%)$ of the group. Field work frequency varied very little with career stage, between 1.4 and 1.5 trips over two years, and roughly a third of the respondents at each career stage had no fieldwork travel. No fieldwork is expected for those who work on modeling, remote sensing, or computational aspects of polar sciences.

\subsubsection{Workshops and small meetings}

Workshops and small meetings were not as popular as larger scientific conferences, but they were attended on average 1.3 times over the two years. ECRs from Africa and Oceania reported the most frequent attendance at these meetings averaging 2.0 per two years each. Despite the moderately low frequency, these events were popular with ECRs: $68 \%$ attended at least one, and of those who attended few events (4 or fewer over the two years), $48 \%$ attended at least one small workshop. Indigenous people attended workshops far less frequently than others, averaging only 0.3 events in that time. The reasons for the low attendance of Indigenous ECRs at these events is not clear in the data we have collected but is something for workshop organizers to consider, especially given that these are a popular event for ECRs as a whole.

\subsubsection{Polar science community meetings}

Most ECRs do not attend polar science community meetings, with $68 \%$ attending none of these events in the last two years. These are meetings where the primary focus is on the business of working groups, associations, or committees. Sometimes these will have an associated scientific conference, but the survey question asked about those for which the primary purpose was not the scientific meeting. On average, each ECR attended 0.6 of these over two years, with a small amount of geographic variability (South America at 0.3 , Oceania at 1.3).

\subsubsection{Career development}

Relatively few ECRs were traveling to events where the primary focus was career development. The most likely career stages to attend were $\mathrm{PhD}$ students and post-docs $(37 \%$ each), who are in training roles focused on a career transition. ECRs from Oceania attended significantly more than other geographic groups, with $62 \%$ traveling for at least one 
career development event and the whole group attending on average 1.8 per two years.

\subsubsection{Field schools}

Field schools were the least frequent type of travel, with ECR respondents traveling to an average of 0.5 field school over the two years. Masters students and respondents from Africa and Asia were the most likely, with $0.8,1.3$, and 0.8 trips over the period respectively. Indigenous people were the least likely, attending only 0.2 over two years on average, and may lack access to the educational institutions and financial support required to participate. This disparity came from both the numbers of field programs that people were attending and the number of people going: for indigenous respondents, $80 \%$ attended none. $37 \%$ of masters students attended at least one field school, but those that did were more likely to attend more than one. For comparison, $44 \%$ of $\mathrm{PhD}$ students attended field schools but averaged fewer of these than for masters students.

\subsubsection{Other events}

$39 \%$ of survey respondents described traveling at least once for other reasons for their work. These included training and preparation for fieldwork and equipment testing, collaborations with other universities, scholar in residence or other short-term fellowships, speaking engagements, job interviews, archive and library visits, using lab facilities, stakeholder interviews, and trips to secure visas for other work travel. The likelihood of needing to travel for other reasons increased with career stage (31\% of masters students versus $48 \%$ of faculty), and ECRs made on average 1.0 such trip every two years. ECRs from Oceania and Europe attended the most of these events (1.5 and 1.2 over two years respectively) and those from North America and Asia attended the fewest (0.6 for each).

\subsection{Cost per trip}

The average reported trip cost EUR 1312. Spending generally increased with career stage, with masters students spending an average of EUR 1259, PhD at EUR 1188, post-docs at EUR 1367, and junior faculty at EUR 1745. Figure 2 shows the cumulative distribution of trip costs for the group as a whole (black) and by continent of origin (colors). Europe was more likely than other geographic groups to have lower travel costs, while Asia and Oceania were significantly less likely to spend under EUR 2000 on a trip.

\subsubsection{Regional variability in travel costs}

European travel costs were substantially lower than those departing from other continents. Because of the high number of meetings and workshops taking place in Europe, the relative ease of travel, and the near proximity of countries to

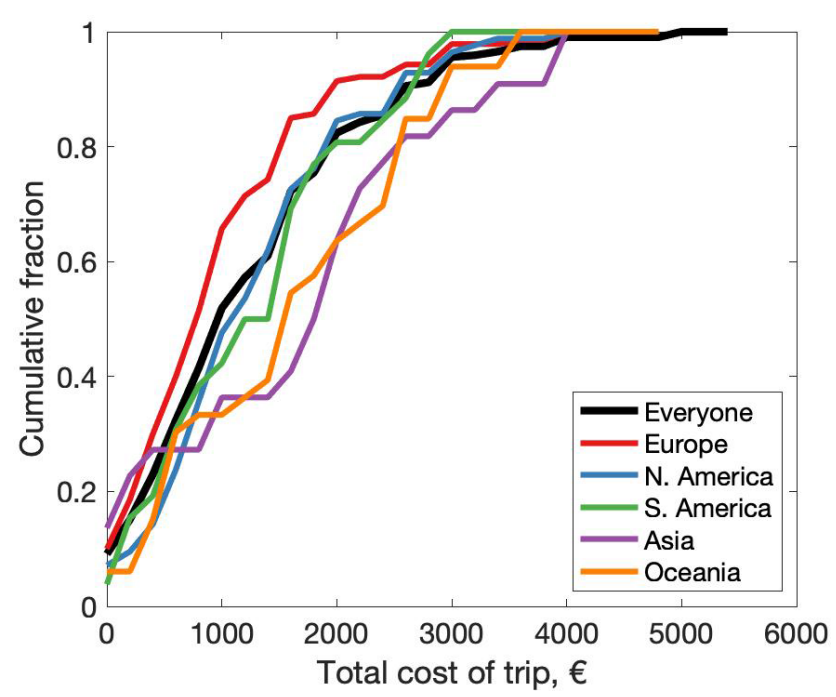

Figure 2. Cumulative distribution functions describing the reported spending on professional travel for the geographic groups indicated. The lines indicate the fraction of reported travel events from each of those geographic groups that spent up to the amount on the $x$ axis. A distribution curve to the left of the black line indicates that group was more likely to spend less than average and farther to the right indicates increasingly higher likelihood of spending a lot more than average. Africa was omitted from this figure because of the low number of responses.

one another, average international travel costs were very low (EUR 1260). For other starting locations, costs were around or above EUR 2000. North America had surprisingly high travel costs, but that may be related to a relative abundance of travel funding and therefore less incentive to cut costs.

US ECRs are far more likely to be making domestic trips (74\% of events attended) than everyone else (29\%). This presumably is due to the large size of the country, the number of meetings and events taking place there, and increased difficulty securing funding for international travel. Domestic travel costs in the United States are much lower than international travel (EUR 955 versus EUR 2535), comparable to the average travel costs for Europeans on all trips (EUR 1000).

\subsubsection{Distance traveled}

Distance traveled per trip highlights the geographic disparities in travel experiences. Europeans travel, on average, $2934 \mathrm{~km}$ for an international event (roughly the distance between Reykjavik, Iceland and Madrid, Spain) and just $488 \mathrm{~km}$ for a domestic event, reflecting the relative ease and convenience. In North America, the average domestic trip is $2268 \mathrm{~km}$, and the average international trip $6577 \mathrm{~km}$, the distance between New York City and Berlin, Germany. With some slightly smaller countries, the domestic travel distances in South America averaged $1663 \mathrm{~km}$, but the average international trip was $10659 \mathrm{~km}$, the distance from Rio to Berlin. Asia had slightly more moderate international travel 
distances at $8273 \mathrm{~km}$, likely due to the effect of a handful of Russian ECRs who had been classified as a whole as being "in Asia" despite Moscow's location in Europe. Oceania required a staggering $19195 \mathrm{~km}$ of average travel distance: this survey did not ask about time or lost hours of productivity, but it is not atypical for ECRs traveling from New Zealand or Australia to describe upwards of $36 \mathrm{~h}$ of one-way travel time to arrive at a three-day meeting.

\subsubsection{Didn't attend because of cost}

ECRs from all over the world have decided not to attend one or more career-relevant meeting during the past two years because of the cost of attendance (74\% of all the participants). Eight out of 10 indigenous people said the same. ECRs working in South America were the most likely to have opted not to travel because of cost $(85 \%)$, followed by Asia (79\%), Oceania (77\%), Europe (74\%), North America $(68 \%)$ and Africa (67\%). Master Students were most likely to be unable to attend career-relevant meetings because of cost $(94 \%)$, followed by Faculty members ( $85 \%)$, then by PhD Students (71\%) and Post-Docs (65\%). Faculty members are more likely to have to pay full cost for registration fees, and may be less likely to have access to shared accommodations. All ECRs who are unable to attend careerrelevant events because of cost are at a disadvantage, but the disparities in the likelihood of missing opportunities because of cost speaks to the challenges in fostering a diverse ECR community.

\subsection{Where did the funding come from?}

For each event that respondents described, they were asked to indicate what percentage (to the nearest $25 \%$ ) came from each of several funding sources: research grant (the one that funds the ECR and/or related projects), event-provided travel support, organization support for ECR representative travel (i.e., IASC Fellows), institutional travel grant, national funding body travel grant, personal funds, and other sources. These responses were then used to investigate both who has access to these funding mechanisms, and what disparities exist in the travel supported by the different sources.

\subsubsection{Research grant funding}

Research funds paid for $27 \%$ of early career travel to events, as indicated in orange in Fig. 3. Research funding pays for a larger share of travel for Europe (30\% of reported travel) and North America (30\%) than for other locations (15\%-25\% by continent). Indigenous participants were much less likely to be using research funds, with research funds accounting for only $4 \%$ of their travel support on all trips; this covered only $50 \%$ of the total costs on trips that were funded at all by research funds. Masters students were also much less likely than average to be able to use research funding (understandably) with $9 \%$ and instead relied heavily on personal funds.

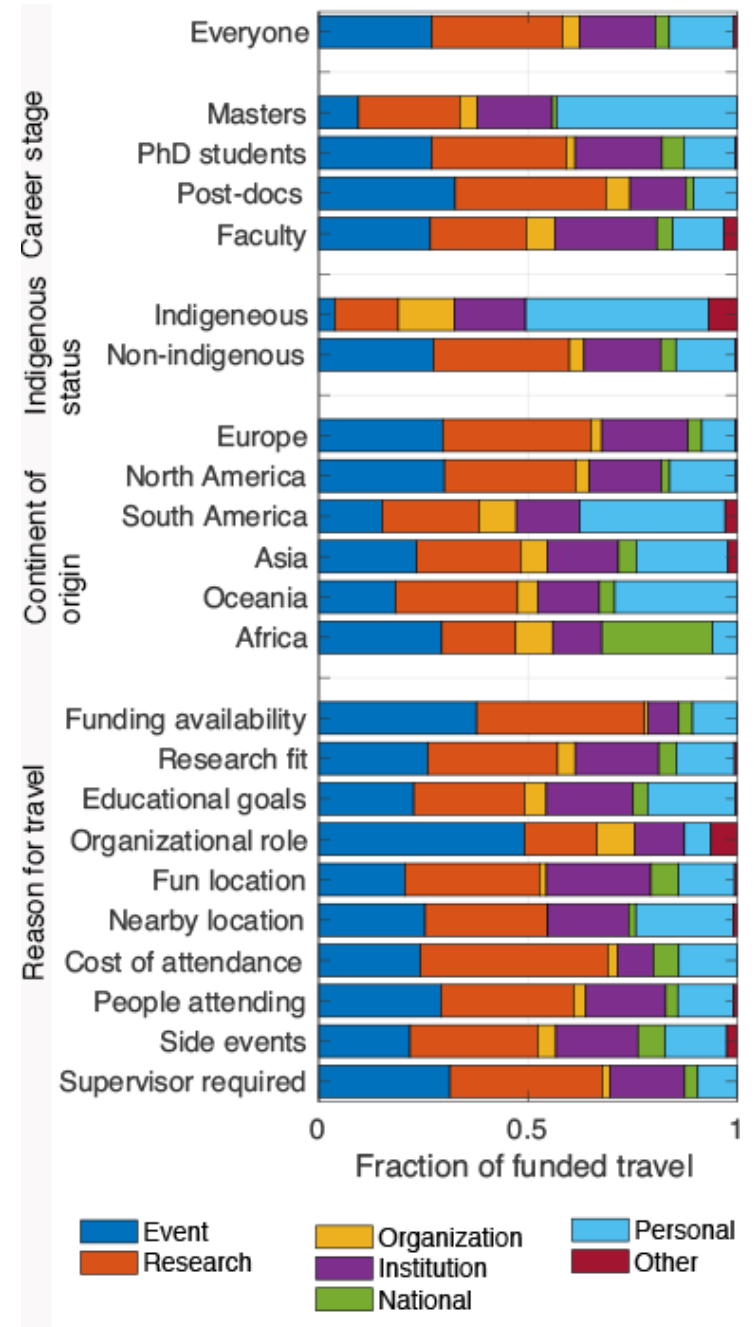

Figure 3. Breakdown of travel funding sources per event by career stage, indigenous status, region, and reason for travel. Each bar shows the fraction of funding for travel to events attended by those meeting the description that comes from each of the listed sources.

Those traveling using research funds were slightly more likely to be presenting their work $(81 \%)$ than the group as a whole $(74 \%)$. They were also more likely to be required to present $(62 \%)$ as a condition of their funding relative to the group $(51 \%)$. There was not a significant difference in presenting requirements between those who received any research funding for travel and those who funded their travel primarily ( $\geq 50 \%$ ) using research funds.

\subsubsection{Event-based support}

Event-based travel support was the largest source of support for early career researchers as a whole, representing an average of $31 \%$ of funding for the reported trips and indicated in dark blue in Fig. 3. This varied with demographic groups: at the high end, Europeans received $35 \%$ of their funding from 
events, post-docs received $36 \%$ and North Americans $31 \%$. For comparison, indigenous respondents received $15 \%$ and respondents from Africa received $18 \%$ of their travel funding from events. These lower numbers suggest that partial travel support (see Sect. 3.4.1) is covering a smaller fraction of costs for ECRs from harder to reach locations.

For participants who received event funding, the average amount was EUR 1037. This covered an average of $75 \%$ of the costs for the events for which they received the funding, reflective of the prevalence of partial travel support awards. For Europeans who used event-based support, the funding covered $84 \%$ of their travel costs. For post-docs, this number was $78 \%$. Indigenous respondents using event-based funds only had $67 \%$ of their travel costs covered, and those from Asia, Oceania, and South America had 55\%, $60 \%$, and $72 \%$ respectively.

When ECRs with access to event-based support were attending an event because of the side events, $88 \%$ of their travel costs were covered. This highlights an approach that many ECR use to make up for limited travel budgets: leverage travel funding for a small side-workshop to attend a larger conference. Those attending because of the cost of attendance $(84 \%)$ or that it was required by their supervisor $(81 \%)$ also were able to cover most of their expenses.

Of ECRs receiving event-based support, $67 \%$ cited the funding as a reason for them to attend. Only $44 \%$ indicated that the event was a particularly good fit for their research, a similar fraction to those traveling because the event was in a fun location (43\%).

Perceived availability of event-based travel support varied as much or more than the travel support itself. Most indigenous respondents described event-based support as either not available (38\%) or highly competitive (37\%). $55 \%$ of those from Oceania described this funding as not available, as did early career faculty. Survey respondents from Asia had the most optimistic view of event-based support, with $24 \%$ describing it as guaranteed. With a limited number of ECRs from Asia applying for event-based funds alongside larger numbers from Europe and North America, they may have a higher likelihood of receiving funding if meeting organizers are selecting for geographic diversity.

\subsubsection{Organizational roles}

Organizational roles paid for only $4 \%$ of the travel support that ECRs documented in this survey, with only 22 reported trips using organizational funds. When travel was supported through an organizational role however, it paid for on average $59 \%$ of travel costs at EUR 1239. Postdocs accounted for 11 out of those 22 trips.

Funding through organizational roles tended to favor those who were underrepresented in the broader group: $13 \%$ of travel support for indigenous participants came through organizational roles as opposed to $4 \%$ for the larger group. Participants from from South America (9\%), Asia (6\%), Oceania
(5\%), and Africa (9\%) also received a larger than average share of funding through these means. North America and Europe were less likely to be supported with an organizational role, accounting for $3 \%$ of funding for each. This suggests that this particular funding mechanism may be being used to support diversity in the polar sciences. These roles typically require more effort and more sustained commitment than event-based funding, requiring extra work of the otherwise underfunded groups, but that extra effort may be valuable for other reasons, as per Majaneva (2016).

\subsubsection{Use of personal funds}

Despite efforts to provide travel support for indigenous participants, $62 \%$ of trips by indigenous ECRs used personal funds to cover travel costs. ECRs from Europe are substantially less likely to have needed to use any amount of personal funds $(15 \%)$ than those from anywhere else. North America also had a relatively low number, at $31 \%$, while those from South America, Asia, and Oceania are much higher (63\%, 48\%, and $45 \%)$. Masters students are much more likely $(60 \%)$ to have spent any amount of personal funds on their last three travel experiences than others $(24 \% \mathrm{Phd}$, $20 \%$ Postdoc, $35 \%$ faculty). The disproportionate reliance by some groups of ECRs reflects a lack of other available funding sources, and should be considered by event organizers when dispersing travel awards.

Personal funds are indicated in bright blue in Fig. 3. All demographic groups used some personal funds to support their travel, but the amount relative to their total travel costs varied substantially. Indigenous participants paid for an average of $44 \%$ of their travel costs with personal funds, as compared to $14 \%$ for non-indigenous respondents in the survey. For organizations seeking to increase the representation of Arctic Indigenous people at workshops and meetings, substantial increases in travel award amounts are needed to reach equity with non-indigenous participants. Other groups that required substantial personal funds were masters students (43\% of total travel costs), reflecting limited other avenues and perhaps being less competitive when it comes to eventbased travel support and those from South America (35\%), and Oceania (29\%), reflecting higher costs of travel and perhaps fewer available resources. Participants attending meetings nearby paid for a relatively high amount out of personal funds ( $23 \%$ ), as did those going because of educational goals $(21 \%)$. Groups reporting particularly low use of personal funds included those from Europe ( $8 \%$ of total travel expenses), post-docs (10\%), those attending because of a role in the organization $(6 \%)$, and those attending because their supervisor required it $(9 \%)$. This underscores the idea that Europeans have more access to travel support than others, and post-docs often have some travel budget that comes with either the position or the research grant funding it. That $9 \%$ of travel costs to events required by their supervisor came 
out of pocket is indicative of the prevalence of the expectation that ECRs pay to participate in these scientific activities.

Of those who used personal funds in attending an event, personal funds covered an average of $54 \%$ of their total event costs, averaging EUR 597. For those using any amount of personal funds, research grants and fellowships covered an average of $15 \%$ of their travel costs, event funding covered $12 \%$, and their home institutions covered $16 \%$. ECRs required to use personal funds were not likely to be even partially covered by organizational travel support or travel awards from national funding bodies, suggesting that these sources tended to provide enough funding to not require personal funds.

The average cost of trips that required the use of personal funds was slightly higher (EUR 1410) than those that did not (EUR 1273). Among the differences between those who used personal funds and those who did not was their access to Research and Event funds, covering $32 \%$ and $39 \%$ respectively of their travel in cases where personal funds were not required and $15 \%$ and $12 \%$ in cases where they were. This would suggest that personal funds are being used to supplement low availability of research funding, and increasing event-provided travel support would directly offset the use of personal funds. Earlier notifications regarding travel support decisions would also allow ECRs to take advantage of lower ticket costs, further reducing the need for personal funds.

\subsection{Travel funding options}

\subsubsection{Utility of partial travel funding}

Many funding sources, including event-based funding and internal institutional travel grants, will offer only partial funding. Others may expect that ECRs find or at least apply to other sources as an indication that they are serious about wanting to attend a particular event. The problem with this approach comes when there are inequalities in the availability of additional funding sources to apply to. Partial funding is considered at least somewhat useful by most of the participants $(66 \%)$, including both those that find it useful because they believe they will be able to find additional funding to supplement a partial award (46\%) and those who expect to pay for at least some of their travel out of personal funds and think every little bit will help (19\%).

Masters students are the most likely career stage to find partial funding entirely unhelpful $(25 \%)$, which would follow from both having limited personal resources to invest in their research-related travel and having few other options. Indigenous ECRs are the most likely to describe partial funding as helpful because every bit of additional funding helps (40\%) and not very helpful because supplementing the partial funding with personal or other funds means not attending another event (30\%). ECRs from North America and Europe are the most likely to describe having other funding options to supplement partial funding ( $51 \%$ and $56 \%$ ), while those

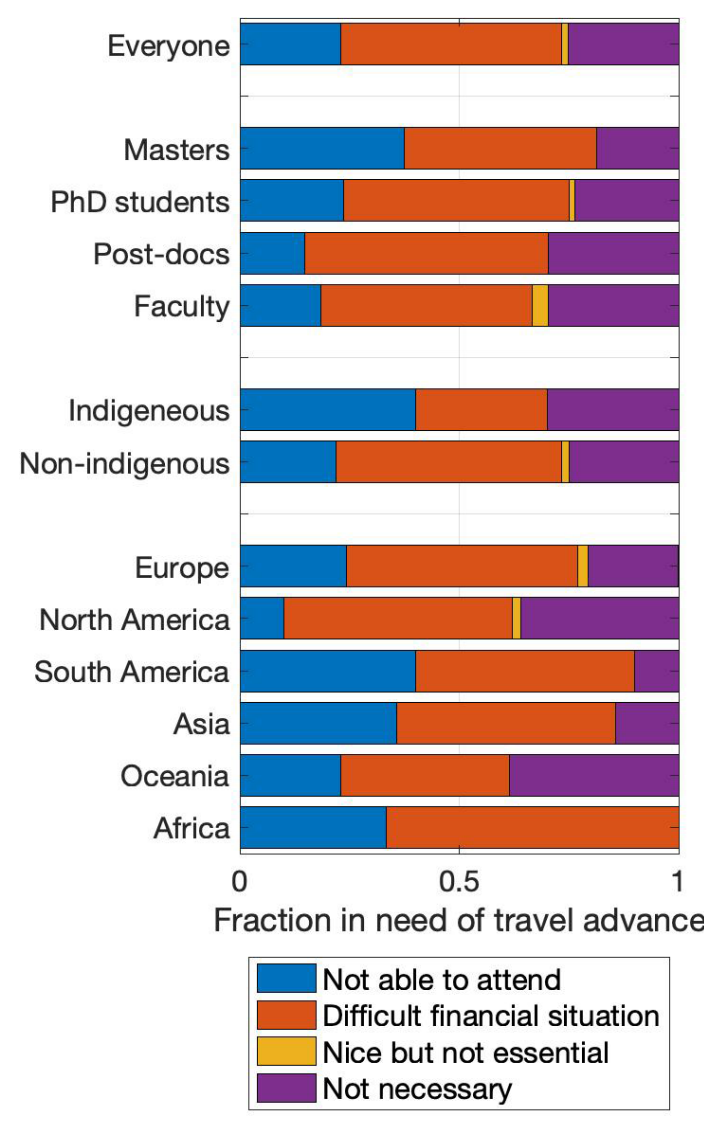

Figure 4. Fraction of survey responses that described varying levels of need for a travel advance. Blue indicates a travel advance is critical to attending the meeting or event, red that it would put the ECR in a difficult financial situation to travel without an advance, yellow that it would be appreciated but is not necessary, and purple that the ECR would not use it.

from South America are the most likely to appreciate needing to pay for less out of pocket $(45 \%)$.

\subsubsection{Necessity of a travel advance}

The option to receive a travel advance is of critical importance for ECRs because $23 \%$ reported that they would not have been able to travel without one and another $50 \%$ said that needing to wait to be reimbursed would put them in a difficult financial situation. The absolute need for a travel advance decreases with advancing career stages, from master students $(38 \%)$ and $\mathrm{PhD}$ students $(24 \%)$ to postdocs $(15 \%)$ and faculty (19\%) (Fig. 4). The increase from postdocs to faculty might be a consequence of the higher personal expenses of the latter at a stage when many are purchasing homes or starting a family, or that many postdoc positions come with with some sort of travel budget. Respondents from indigenous communities and South America relied more on travel advance ( $40 \%$ each) than any other group, followed by Asia (36\%), Africa (33\%), Oceania (23\%), Europe (24\%) 


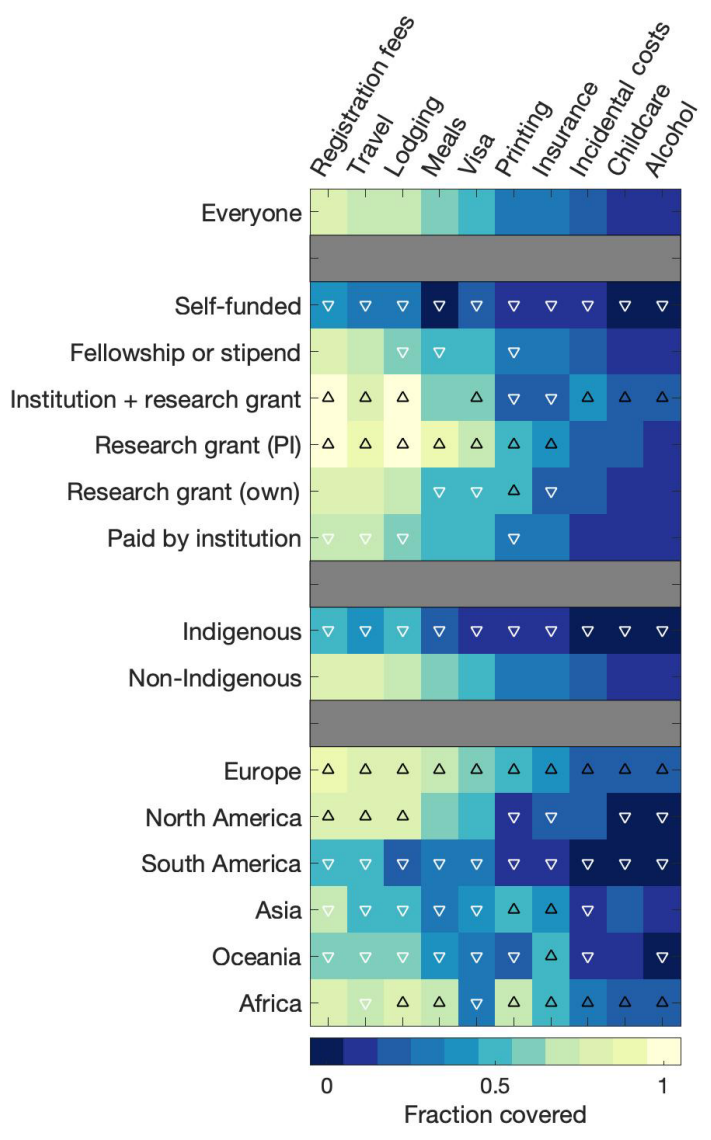

Figure 5. Likelihood that a travel-related expense is covered by travel support funding for different demographic groups. The colormap shows the fraction of respondents who reported having an expense covered by travel funding, with everyone in the top row and demographic groups in the following rows. The black up arrows indicate that a particular group is more likely than average to have an expense covered by travel funds, and the white down arrows indicate that they are less likely. Close to the group average (within $5 \%$ ) is left without an arrow.

and North America (10\%). This data, shown in Fig. 4, suggests that some groups and regions are more vulnerable than others since many funding sources can only accommodate reimbursements. The standard of reimbursements is effectively a loan of up to several thousand euro, made from an early career researcher to an institution over the period between when travel is booked and the reimbursement processed, a loan that many ECRs cannot afford to make.

\subsection{Covered Expenses}

Registration fees, travel and lodging are the expenses more commonly covered by the funding sources $(>70 \%)$, whereas alcohol, childcare and incidental costs were the least likely to be covered $(<20 \%)$. Lack of funding for childcare costs increases the financial burden for ECRs with young families or limits their ability to attend altogether. In general,
ECRs funded totally or partially by a research grant (their own or from the PI) had more expenses covered, closely followed by students with a fellowship, with the least expenses covered for self-funded students (Fig. 5). Again respondents from indigenous communities and South America reported fewer expenses as being covered by their funding sources (e.g. less than $50 \%$ for registration fees) followed by Asia, Oceania, North America, Africa and Europe (Fig. 5). This shows that some groups are more vulnerable than others since their funding sources cover fewer expenses than others. This tracks with the uneven use of personal funds: groups less likely to have their expenses covered by research, institutional, or event funds are more likely to have to pay for those things out of pocket.

\section{Conclusions}

Our survey of ECR travel to polar science events shows that funding opportunities to attend scientific conferences, field schools and workshop are not equally distributed across career stage or geography. Cost per trip increases with career stage, which may reflect greater access to funding with career stage in addition to potentially higher expenses. The transition from reduced early career registration fees and less flexibility with regard to work schedules increase costs. Older ECRs are more likely to have family responsibilities that either increase travel costs (bringing a child to a meeting and not being able to share a room) or reduce flexibility (can't wait an extra day for a lower-cost ticket), though graduate students and post-docs can have families as well. ECRs from the US are more likely to undertake domestic than international travel, but these costs remain high due to the vast domestic travel distances. International travel costs are lowest for ECRs traveling from Europe, reflecting the greater number of events, shorter travel distances and more extensive travel options available in Europe. Travel costs increase with distance travelled. ECRs from South America and Oceania traveling the furthest and require larger amounts of funding (and time) to attend. When ECRs had sufficient access to funding, they overwhelmingly chose to attend scientific conferences. Scientific conferences are the most popular research-related type of travel, followed by fieldwork and smaller workshops. Three-quarters of all survey participants have not attended one or more career-relevant events during the past two years due to the cost of attendance, and this is an issue for ECRs from all continents at all career stages. A worrying number of survey respondents relied on personal funds to attend these events, which risks limiting access to important opportunities for career development to those without personal funds to spare, inhibiting efforts towards more diversity in the polar sciences.

Some of the comments and personal experiences gathered by the survey highlighted the importance of advance notice of the availability of partial or complete travel support. Ac- 
cording to these experiences, advance notice allows ECRs to reduce the costs associated with lodging, registration fees (i.e., early bird versus regular registration) and especially traveling (e.g., airfares), which is particularly important if ECRs are only receiving partial travel support and they are covering some of these expenses with their own money. Furthermore, we are aware of at least one case where the ECR was awarded complete travel support, but could not attend because notification of the travel support was so close to the event that there was insufficient time to apply for a visa to attend the event. It is clear from these comments that funding organizations do not always consider the time required to apply for visas or the time lead needed to minimize travel costs. The further in advance an award can be announced, the more time ECRs have to look for additional funds and apply for visas. A consideration of these points may help to increase the inclusion of ECRs and boost diversity at these events. Therefore, we recommend that national and international funding bodies notify potential participants of the outcome of travel support calls as early as possible, as a practice geared towards promoting the participation of ECRs and the diversity of the attendees.

Based on the results of the survey, organizations and institutions that fund early career travel should make an effort to make travel advances available as needed, since more than $50 \%$ of ECRs said that attending these events would put them in a difficult financial situation while another $23 \%$ would not be able to attend without one. Attendees at earlier career stages (e.g. masters and $\mathrm{PhD}$ students), indigenous ECRs and those from certain continents (e.g. South America, Asia and Africa) depend more on the availability of a travel advance to avoid having to front sometimes thousands of euros for several months. Replacing travel reimbursements with advances would promote the participation of certain groups that tend to be underrepresented in these events. Event organizers trying to increase the diversity of their attendees should keep in mind the differing travel costs and other funding resources available to ECRs from different parts of the world.

Recently the Scientific Committee on Antarctic Research Executive Committee has shown their commitment to reducing the carbon footprint related to the scientific traveling of the Antarctic community (see details in SCAR, 2019b). One of the actions suggested is to include live electronic participation for all future meetings. Though planned as a way to reduce the carbon footprint, this could also have a positive effect on the diversity of the attendees and boost the participation of groups that are often underrepresented at these events due to lower availability of funds, higher travel costs, visa restrictions, etc. We recommend the incorporation of live electronic participation in these events (e.g. workshops and conferences) as a standard procedure that will help to increase attendee diversity while reducing their carbon footprint, both current and pressing issues within the scientific community. Continued effort and meeting planning is required to ensure that remote attendance confers the same benefits as in-person attendance: networking opportunities (and even the chance to ask questions) are limited for remote access to meetings held predominately in-person.

With the Covid-19 pandemic, many meetings and workshops have moved online. The Arctic Observing Summit 2020 was held as a series of live calls over four days, scheduled to accommodate time zones around the world (https: //aos2020agenda.org, last access: 17 June 2020). The European Geophysical Union General Assembly moved to an online format (EGU2020: Sharing Geoscience Online, https: //www.egu2020.eu, last access: 17 June 2020), with scheduled sessions much like a standard scientific conference. We encourage event organizers to collect information from participants to see if this shift to an online setting has made the meeting accessible to a more diverse early career audience than normally attends. We hope that these meetings can serve as a model moving forward: while online meetings do not seem to be a total replacement for in-person interaction, if well organized they can serve many of the functions at a fraction of the cost to early career participants.

There is some ambiguity on the utility of partial funding. Two-thirds of respondents consider it useful but this varied with geography and career stage and perhaps reflects that in some places there are few funding sources from which ECRs can top up their travel costs. $40 \%$ of indigenous ECRs consider partial funding to be helpful in offsetting use of their own money, while $44 \%$ of their travel expenditures came from personal funds. This suggests that travel opportunities for this group are mostly limited to those who have access to personal funds. If there is a prevailing belief that professional travel requires the use of personal funds, every little bit of extra support helps.

We recommend that organizations that provide early career travel support consider how their funding model impacts the ECRs they support. Especially for larger organizations who support a lot of workshop travel (e.g., SCAR, IASC), there is an opportunity for a more focused study of how travel funding is being used across the groups of ECRs who receive it. A global survey of the financial state of early career researchers in the polar sciences would also help in building community understanding of the inherent inequalities in the system. Finally, some sort of study of the actual benefits that researchers (not just early career) receive from attending meetings and workshops would benefit the community as a whole: there is a sense that this kind of travel is very important, but little information on why exactly.

Travel to networking and career development events is critical for the career advancement of polar researchers. Still, for many, attendance at these events incurs considerable travel costs that are not always met by research grants and institutional funding. In many cases, ECRs are topping up partial support with personal funds. Partial funding is more helpful for ECRs who have access to a variety of funding sources and increasing the availability of event-provided travel sup- 
port would directly offset the use of personal funds in underrepresented groups. Providing a travel advance, rather than a travel reimbursement, would support ECRs who are not in a financial position to pay for travel costs upfront, and would reduce financial hardship for many others. Live electronic attendance could increase accessibility to workshops and conferences, provided this facilitates the networking opportunities that are so important to early career researchers. It is less appropriate for field schools and some types of training courses. Following these recommendations would help to even out some of the inequalities in access to appropriate travel support.

Data availability. The data is not publicly accessible. Interested parties can contact the corresponding author for information and/or data.

Supplement. The supplement related to this article is available online at: https://doi.org/10.5194/adgeo-53-73-2020-supplement.

Author contributions. AB proposed and drafted the survey, all authors revised the survey and contributed to the analysis of results: $\mathrm{CE}$ related to responses and demographics, $\mathrm{AB}$ regarding funding for individual events and costs, VS about travel advances and frequency of travel, and $\mathrm{JH}$ regarding what gets covered. All authors contributed to drafting the manuscript, and $\mathrm{AB}$ prepared the figures.

Competing interests. The authors are serving or have served in the leadership of the Association of Early Career Polar Scientists (APECS), Alice Bradley as President in 2016-2017, on the executive committee 2014-2018 and as Chair of USAPECS 20142016, Juan Höfer on the executive committee 2018-2020, Valentina Savaglia on the Council (APECS Belgium chair) from 2018-2020, and Clare Eayrs was on the Executive Committee 2018-2019. This project started as a working group of the APECS council and used APECS web resources, including the membership mailing list. The statements made in this paper represent those of the Authors and are not an official position of APECS as an organization.

Special issue statement. This article is part of the special issue "Diversity and equality in the geosciences (EGU2019 EOS6.1 \& US4, AGU2018 ED41B, JpGU2019 U-02)". It is not associated with a conference.

Acknowledgements. The authors would like to thank everyone who participated in or shared the survey, the two reviewers who provided immensely helpful comments, and to everyone who has dedicated funds to help support early career travel.
Review statement. This paper was edited by Elena Toth and reviewed by Emma C. Smith and Elena Toth.

\section{References}

APECS, Association of Polar Early Career Scientists: APECS Annual Report 2017-2018, available at: https://www.apecs. is/who-we-are/publications/annual-reports/details/36/1.html, 2018.

Arctic Council Agreement on Enhancing International Arctic Scientific Cooperation, signed at the Fairbanks Ministerial meeting, available at: http://hdl.handle.net/11374/1916 (last access: 17 June 2020), 11 May 2017.

ARCUS, Arctic Research Consortium of the US: Calendar of Events, available at: https://www.arcus.org/events/ arctic-calendar (last access: 17 June 2020), 2019.

Bankston, A. and McDowell, G. S.: Monitoring the compliance of the academic enterprise with the Fair Labor Standards Act. F1000Research, 5:2690, https://doi.org/10.12688/f1000research.10086.2, 2017.

Cuker, B. E., Haxton, C., and Martinez, C.: How a Scientific Society Built Multicultural Diversity: A 25-Year-Long Journey, BioScience, 66, 238-244, https://doi.org/10.1093/biosci/biw001, 2016.

Gewin, V.: Polar research should include Indigenous perspectives, Nature, 453-453, 2019.

Gleßmer, M. S., Wang, Y. V., and Kontak, R.: Networking as a tool for Earth science women to build community and succeed, Eos T. Am. Geophys. Un., 93, 406-407, 2012.

Green, E.: Graduate Students Escaped Tax Increases, but They Still Feel a Target on Their Backs, New York Times, available at: https:/www.nytimes.com/2017/12/19/us/ politics/graduate-students-education-tax-bill.html (last access: 17 June 2020), 19 December 2017.

U.S. Interagency Arctic Research Policy Committee (IARPC): Principles for Conducting Research in the Arctic, available at: https://www.iarpccollaborations.org/uploads/cms/documents/ principles_for_conducting_research_in_the_arctic_final_2018. pdf (last access: 17 June 2020), 2018.

IASC, International Arctic Science Committee: IASC Strategic Plan 2018-2023, available at: http://iasc.info/images/ about/organization/StrategicPlan2018_layout_web.pdf (last access: 17 June 2020), 2018.

IASC, International Arctic Science Committee: ASSW 2019 Travel Support, available at: https://iasc.info/communications/ news-archive/512-assw-2019-travel-support-available (last access: 17 June 2020), 2019a.

IASC, International Arctic Science Committee: Congratulations to the 2019 IASC Fellows, available at: https://iasc.info/communications/news-archive/ 503-congratulations-to-the-2019-iasc-fellows (last access: 17 June 2020), 2019b.

IASC, International Arctic Science Committee Action Group on Indigenous Involvement: Report from the IASC Action Group on Indigenous Involvement, available at: https://iasc.info/ images/action-groups/AGII_Report_20200323.pdf (last access: 17 June 2020), 2020. 
Majaneva, S., Hamon, G., Fugmann, G., Lisowska, M., and Baeseman, J.: Where are they now? A case study of the impact of international travel support for early career Arctic researchers, Polar Sci., 10, 382-394, 2016.

MoChridhe, R.: London School of Economics Impact Blog: Academic travel culture is not only bad for the planet, it is also bad for the diversity and equity of research, available at: https://blogs.lse.ac.uk/impactofsocialsciences/2019/03/19/academictravel-culture-it-is-not-only-bad-for-the-planet-it-also-bad-forthe-diversity-and-equity-of-research/ (last access: 17 June 2020), 2019.

Pfirman, S. L., Bell, R. E., Turrin, M. J., and Maru, P.: Bridging the Poles: Education Linked with Research: A Report on the Workshop: 23-25 June 2004, Washington, DC, 2004.

Provencher, J., Gantner, N., Schmale, J., Swanson, H., and Baeseman, J.: Early Career Researchers and Mentors Work Together to Shape the Future of the Arctic Monitoring and Assessment Programme, Arctic, 65, 115-118, 2012.

Rowe, N.: When you get what you want, but not what you need: The motivations, affordances and shortcomings of attending academic/scientific conferences, International Journal of Research in Education and Science, 4, 714-729, https://doi.org/10.21890/ijres.438394, 2018.
SCAR (Scientific Committee for Antarctic Research): NSF Travel Grant Opportunity for ISAES 2019 (US attendees), available at: https://www.apecs.is/news/polar-news/ 2924-nsf-travel-grant-opportunity-for-isaes-2019-us-attendees. html (last access: 17 June 2020), 2019a.

SCAR (Scientific Committee for Antarctic Research): A View From the South VII - Net Zero for SCAR by 2030?, available at: https://www.scar.org/about-us/view-from-south/vfts7/ (last access: 17 June 2020), 2019b.

SEARCH: Study of Environmental Arctic CHange, Arctic Futures 2050: Early Career Travel Award, available at: https: //www.searcharcticscience.org/arctic-2050/conference-2019/ early-career-support (last access: 17 June 2020), 2019.

Urban, E. and Boscolo, R.: Using Scientific Meetings to Enhance the Development of Early Career Scientists, Oceanography, 26, 164-170, 2013. 